\title{
Hemşirelik Öğrencilerinin Klinik Ortamdaki Doyum Düzeyleri ve Etkileyen Faktörler
}

\author{
Related Factors and Satisfaction Levels of Nursing Students in Clinical Settings
}

\author{
Ayşe TAŞTEKIN**, Büşra TÜRKDÖNMEZ**, Merve GÜLER**, Ayşegül YILMAZ** , Tülay ERŞAHAN**
}

İletişim/Correspondence: Ayşe TAŞTEKİN Adres/Address: Afyon Kocatepe Üniversitesi, Afyon Sağlik Yüksekokulu, Hemşirelik Bölümü, İzmir Karayolu 5. km. Ali Çetinkaya Kampüsü Afyonkarahisar Tel: 027224628 34/ 71104 Fax: 02722462869 E-mail: ayse.koyun@hotmail.com

\section{$\ddot{O} Z$}

Amaç: Bu çalışmanın amacı hemşirelik öğrencilerinin klinik ortamdaki doyum düzeylerini ve etkileyen faktörleri değerlendirmektir.

Yöntem: Bu çalışma tanımlayıcı bir çalışmadır. Çalışma birsağlık yüksekokulu hemşirelik bölümündeki 225 ögrenci ile yürütüldü. Veriler anket formu ve Öğrenci Duyumu Ölçeği ile toplandı. Verilerin değerlendirilmesinde frekans, korelasyon katsayısı, One-Way ANOVA ve Tukey Testi kullanıldı.

Bulgular: Öğrencilerin klinik uygulamalarda en fazla karşılaştıkları sıkıntılar; klinik uygulama sırasında görevleri dışında sorumluluk almaları ve okulda aldıkları tüm uygulamalı derslerle ilgili kliniklere çıkamamalarıdır. Öğrencilerin Öğrenci doyumu puan ortalamaları orta düzeyin üstündedir. 1. ve 3. sını öğrencilerinin doyumpuanları daha yüksektir.

Sonuç: Klinik uygulamalarda keyifle çalışan, uygulamalarını hemşire ile birlikte yapan, hocalardan yardım alan ve görevi dışında sorumluluk almayan öğrencilerin doyum puanlarl daha yüksektir.

Anahtar Kelimeler: Hemşirelik, klinik uygulama, öğrenci doyumu.

\section{ABSTRACT}

Aim: The aim of this study was to evaluate related factors and satisfaction levels of nursing students in the clinical setting. Method: This study is a descriptive study. The study was conducted with 225 students at a health school nursing department. Data are collected with questionnaire and Student Satisfaction Scale. Data was evaluated by frequency, correlation coefficient, One-Way ANOVA, and Tukey test.

Results: Problems encountered by most students in clinical practice; take responsibility tasks outside and can not go to areas related to clinical courses. Student satisfaction score of students are above the middle level. Satisfaction scores of the 1st and 3rd grade students are higher.

Conclusion: Satisfaction scores of students who enjoy working in clinical practice, practices with nurse, assistance from teacher, and don't take responsibility for tasks outside are higher.

Keywords: Nursing, clinical practice, student satisfaction. *Yrd. Doç. Dr. Afyon Kocatepe Üniversitesi Afyon Sağllk YüksekokuluHemşirelik Bölümü, **Hemşirelik 4. Sinıf Öğrencisi Afyon Kocatepe Üniversitesi
Afyon Sağlık Yüksekokulu

Yazının gönderilme tarihi: 07.09.2015

Yazının basım için kabul tarihi: 29.01.2016 


\section{GíRiş}

Türk Dil Kurumu'na göre, doyum “eldekinden hoşnut olma durumu, doyma işi, yetinme, kanma, kanaat" ve "bazı istekleri giderme, tatmin" demektir (TDK 2015).

Öğrenci doyumu,öğrencilerin değişen ihtiyaçlarını karşılamak, kurumsal başarı ve etkinliği değerlendirmek için kullanılan önemli bir ölçüm aracıdır (Svetlana, Beltyukova ve Fox 2002). Literatürde üniversite ögrencilerinin doyumunu etkileyen faktörler; üniversite tesislerinin ve hizmetlerinin erişim ve kullanım1, sosyal olanaklar, üniversitenin yönetim tarzı, akademik ve sosyal bütünleşme, eğitim öğretim faaliyetleri ve kalitesi, eğitimin yararlılığı ve kişiselbeklentiler olarak belirlenmiştir. Öğrenci doyumu sosyal büyümeye, akademik performansa ve motivasyona katkıda bulunur. Memnuniyet düzeyi yüksek öğrencilerinakademik başarılarının daha yüksek olduğu ve amaçlarını gerçekleştirmeye kendilerini daha çok adadıklar1 belirtilmektedir (Elliot ve Shin 2002).

Lee, White ve Hong (2009) çalışmalarında hemşirelik öğrencilerinin klinik ortamda öğrenmelerini kolaylaştıran faktörlerden ve klinik yeterliliği arttırmak için geliştirilen yöntemlerin varlığından bahsetmiş bununla birlikte klinik eğitimde öğrenci doyumu ile ilgili çalışmaların halen yetersiz olduğunu vurgulamışlardır. Türkiye'de yapılan çalışmalarda bazı değişkenler ilehemşirelik öğrencilerinin doyumları ile ilişkisi değerlendirilmiştir. Egelioğlu, Arslan ve Bakan (2011) hemşirelik öğrencilerinin akademik başarılarının; Yangın ve Kurca (2013) ise bölümden memnun olma durumlarının öğrencilerin doyumlarını olumlu yönde etkilediğini belirtmişlerdir. Kantek ve Kazanc1 (2012) ile Özdelikara ve Babur (2016)'un çalışmalarında hemşirelik eğitiminin ilk yıllarındaöğrencilerin doyumlarının yüksek olduğu ve öğrencilerin beklentilerinin yeterince karşılanmamasıdurumunda eğitimlerinin sonuna doğru doyumlarının azaldığı tespit edilmiştir.

Yapılan literatür taramasında, Türkiye'de hemşirelik öğrencilerinin klinik ortamda doyum düzeylerini etkileyen faktörleri inceleyen bir araştırmaya rastlanamamıştır. Bu çalışma hemşirelik öğrencilerininklinik or- tamdaki doyum düzeylerini ve etkileyen faktörleri belirlemek amacıyla yapılmıştır.

\section{YÖNTEM}

\section{Araştırmanın Tipi ve Amacı}

$\mathrm{Bu}$ çalışma hemşirelik öğrencilerininklinik ortamdaki doyum düzeylerini ve etkileyen faktörleri belirlemek amacıyla yapılmıştanımlayıcı bir çalışmadır.

\section{Araștırmanın Yeri ve Zamanı}

Bu çalışma 5-16 Ocak 2015 tarihleri arasında yürütülmüştür. Çalışmabir sağlık yüksekokulu hemşirelik bölümü öğrencileri ile yürütülmüştür.

\section{Araştırmanın Evren ve Örneklemi}

Evren 2014 - 2015 eğitim ve öğretim yılında hemşirelik bölümüne kayıtlı olan 320 öğrenciden oluşmaktadır. Bu çalışma için örneklem seçimi yapılmamıştır. Çalışmaya katılmayı kabul eden, ulaşılabilen ve anket formlarını tam dolduran 225 öğrenciden elde edilen veriler değerlendirilmiştir.

\section{Veri Toplama Araçları}

Veriler araştırmacılar tarafından hazırlanmış 15 sorudan oluşan anket formu ve Öğrenci Duyumu Ölçeği - Kısa Form (ÖDÖ) ile toplanmıştır. ÖDÖ, hemşirelik okullarında öğrenim gören öğrencilerin doyumunu belirlemek için Baykal ve ark. (2002) tarafindan geliştirilmiş ve Baykal, Harmancı, Eşkin, Altuntaş ve Sökmen (2011) tarafından tarafından tekrar revize edilmiştir. Öğretim elemanları, okul yönetimi, kararlara katılım, bilimsel-sosyal ve teknik olanaklar ve eğitim-öğretimin niteliği alt boyutlarından oluşan ölçekte bulunan 53 madde 5 "Kesinlikle katılıyorum", 4 "Katılıyorum", 3 "Kararsızım", 2 "Katılmıyorum", 1 "Kesinlikle katılmıyorum”şeklinde değerlendirilmiştir. ÖDÖ’nün Cronbach's alfa katsayıları 0.83 - 0.97 arasında değişmektedir.

\section{Verilerin Değerlendirilmesi}

Verilerin değerlendirilmesinde frekans, korelasyon katsayısı, One-Way ANOVA ve Tukey Testi kullanılmıştır. 


\section{Araştırmanın Etik Yönü}

Çalışma için Afyonkarahisar Klinik Araştırmalar Etik Kurulu'ndan, çalışmanın yapıldığı kurumdan ve öğrencilerden izin alınmıştır.

\section{BULGULAR}

Öğrencilerin yaş ortalamaları $20.6 \pm 1.4$ olarak tespit edilmiştir. Öğrencilerin \%15.6's1 1. sınıf, \%23.6's1 2. sınıf, \%29.3'ü 3. sınıf ve \%31.6'sı 4. sinıftadır. Araştırma sonuçlarına göre, çalışma şartlarının zorluğu (\%71.6), mesleği ile ilgili öğrencilerien çok tedirgin eden faktör olarak tespit edilmiştir. Öğrencilerin $\% 63.6$ 's 1 hastane uygulamaları sirasinda keyifle ve huzurla çalışamadıklarını belirtmişken; \%66.2'si hastaların bakım ve tedavileri konusunda bilgileri doğrultusunda hastaya müdahale edebildiklerini belirtmiştir (Tablo 1).

Öğrencilerin \%33.8'inin bir uygulamayı korkusuz, stressiz ve kendilerini vererek en iyi yalnız başına iken yaptıkları, \%62.7'sinin uygulamalarda en fazla hemşirelerden yardım aldıkları tespit edilmiştir. Öğrencilere klinik uygulamalarda en fazla karşılaştıkları s1kıntılar; soyunma odalarının yetersiz olması (\%34.2), klinik uygulama sırasında görevleri dışında sorumluluk almaları (\%71.1), okulda aldıkları tüm uygulama11 derslerle ilgili kliniklere çıkamamaları (\%54.7), bakım ve tedavilerde ortaya çıkan eksiklik ve aksaklıklardan ötürü suçlanmaları (\%30.2), bakım verdikleri hastanın merak ettikleri bilgilerine ulaşamamaları (\%28.0) ve hastanedeki malzemelerden yeterince faydalanamamalarıdır (\%13.3) (Tablo 1).

Yapılan istatistiksel analizde öğrencilerin sınıfları, hastane uygulamaları sırasında keyifle ve huzurla çalışma durumları, uygulamalarda karşılaştığınız hastalıklarla ilgili merak ettiği konuları sordukları kişiler, korkusuz, stressiz, rahat ve kendini vererek birlikte en iyi uygulama yaptıkları kişiler, uygulamalar da en fazla yardım aldıkları kişiler, hastanelerde soyunma odası vb. imkânlara sahip olmalarının öğrencilerin ÖDÖ puanlarını etkilediği belirlenmiştir $(\mathrm{p}<0.05)$ (Tablo 2).
Öğrencilerin tüm ÖDÖ puan ortalamaları orta düzeyin üzerinde olmakla birlikte; genel olarak 1. ve 3. sinıf öğrencilerinin puan ortalamalarının daha yüksek olduğu gözlenmektedir. 4. sınıf öğrencilerinin ÖDÖ puan ortalamaları diğer öğrencilerden daha düşük bulunmuştur $(\mathrm{p}<0.05)$.

Tablo 1. Öğrencilerin Klinik Uygulamalara İlişkin Görüşleri

\begin{tabular}{|c|c|c|c|}
\hline & & $\mathbf{n}$ & $\%$ \\
\hline \multirow{3}{*}{$\begin{array}{l}\text { Mesleğinizle } \\
\text { ilgili sizi en fazla } \\
\text { tedirgin eden konu } \\
\text { nedir? }\end{array}$} & Çalışma şartları zor & 161 & 71.6 \\
\hline & Geliri az & 22 & 9.8 \\
\hline & Mesleki ilerleme zor & 42 & 18.7 \\
\hline \multirow{2}{*}{$\begin{array}{l}\text { Keyifle ve huzurla } \\
\text { çalışma imkânı } \\
\text { buluyor musunuz? }\end{array}$} & Evet & 82 & 36.4 \\
\hline & Hayır & 143 & 63.6 \\
\hline \multirow{2}{*}{$\begin{array}{l}\text { Hasta bakımında } \\
\text { hastaya müdahale } \\
\text { etme imkânı } \\
\text { bulabiliyor } \\
\text { musunuz? }\end{array}$} & Evet & 149 & 66.2 \\
\hline & Hayır & 76 & 33.8 \\
\hline \multirow{4}{*}{$\begin{array}{l}\text { Korkusuz ve } \\
\text { kendinizi vererek } \\
\text { bir uygulamayı en } \\
\text { iyi kimin yanında } \\
\text { yaparsınız? }\end{array}$} & Hocalarımın & 22 & 9.8 \\
\hline & Hemşirelerin & 54 & 24.0 \\
\hline & Arkadaşlarımın & 73 & 32.4 \\
\hline & Kendi başıma & 76 & 33.8 \\
\hline \multirow{3}{*}{$\begin{array}{l}\text { Uygulamalarınızda } \\
\text { en fazla } \\
\text { kimden yardım } \\
\text { alıyorsunuz? }\end{array}$} & Hemşirelerden & 141 & 62.7 \\
\hline & Hocalarımdan & 34 & 15.1 \\
\hline & Arkadaşlarımdan & 50 & 22.2 \\
\hline \multirow{6}{*}{$\begin{array}{l}\text { Klinik } \\
\text { uygulamalarda } \\
\text { en fazla } \\
\text { karşılaştı̆̆ınız } \\
\text { sorunlar nelerdir? }\end{array}$} & $\begin{array}{l}\text { Görevim dişında } \\
\text { sorumluluk almak }\end{array}$ & 160 & 71.1 \\
\hline & $\begin{array}{l}\text { Uygulamalı derslerle } \\
\text { ilgili kliniklere } \\
\text { çıkamamak }\end{array}$ & 123 & 54.7 \\
\hline & $\begin{array}{l}\text { Soyunma odası gibi } \\
\text { imkânların kısitlı } \\
\text { olması }\end{array}$ & 77 & 34.2 \\
\hline & $\begin{array}{l}\text { Bakımdaki eksiklik ve } \\
\text { aksaklıklardan ötürü } \\
\text { suçlanmak }\end{array}$ & 68 & 30.2 \\
\hline & $\begin{array}{l}\text { Hastamın bilgilerine } \\
\text { ulaşamamak }\end{array}$ & 63 & 28.0 \\
\hline & $\begin{array}{l}\text { Eldiven, maske } \\
\text { gibi malzemelerden } \\
\text { yeterince } \\
\text { faydalanamamak }\end{array}$ & 30 & 13.3 \\
\hline
\end{tabular}


Tablo 2. Bazı Değişkenlere Göre Öğrencilerin Doyum Ölçeği Puanları

\begin{tabular}{|c|c|c|c|c|c|c|}
\hline & & n & $\bar{X}$ & SS & İstatistik & $\mathbf{p}$ \\
\hline \multirow{4}{*}{ Sinif } & 1 & 35 & $181.3^{\mathrm{a}}$ & 25.0 & \multirow{4}{*}{$F=10.697$} & \multirow{4}{*}{0.000} \\
\hline & 2 & 53 & $163.2^{\mathrm{b}}$ & 40.8 & & \\
\hline & 3 & 66 & $175.8^{\mathrm{a}}$ & 31.9 & & \\
\hline & 4 & 71 & $146.7^{\mathrm{b}}$ & 38.9 & & \\
\hline \multirow{2}{*}{$\begin{array}{l}\text { Klinikte keyifle ve huzurla çalışma } \\
\text { imkânı buluyor musunuz? }\end{array}$} & Evet & 82 & 176.0 & 29.5 & \multirow{2}{*}{$\mathrm{t}=3.536$} & \multirow{2}{*}{0.000} \\
\hline & Hayır & 143 & 157.9 & 40.5 & & \\
\hline \multirow{4}{*}{$\begin{array}{l}\text { Korkusuz ve kendinizi vererek bir } \\
\text { uygulamayı en iyi kimin yanında } \\
\text { yaparsınız? }\end{array}$} & Hocalarımın & 22 & $172.7^{\mathrm{a}}$ & 51.0 & \multirow{4}{*}{$F=2.724$} & \multirow{4}{*}{0.045} \\
\hline & Hemşirelerin & 54 & $174.9^{\mathrm{a}}$ & 33.3 & & \\
\hline & Arkadaşlarımın & 73 & $161.2^{\mathrm{b}}$ & 33.1 & & \\
\hline & Yalnız & 76 & $157.9^{\mathrm{b}}$ & 39.5 & & \\
\hline \multirow{3}{*}{$\begin{array}{l}\text { Uygulamalarınızda en fazla kimden } \\
\text { yardım alıyorsunuz? }\end{array}$} & Hemşirelerden & 141 & $167.7^{\mathrm{a}}$ & 40.8 & \multirow{3}{*}{$\mathrm{F}=3.857$} & \multirow{3}{*}{0.023} \\
\hline & Hocalarımdan & 34 & $170.3^{\mathrm{a}}$ & 31.7 & & \\
\hline & Arkadaşlarımdan & 50 & $151.7^{\mathrm{b}}$ & 29.8 & & \\
\hline \multirow{2}{*}{$\begin{array}{l}\text { Klinikte göreviniz dişında sorumluluk } \\
\text { alıyor musunuz? }\end{array}$} & Evet & 160 & 160.8 & 37.9 & \multirow{2}{*}{$\mathrm{t}=-2.347$} & \multirow{2}{*}{0.020} \\
\hline & Hayır & 65 & 173.7 & 36.2 & & \\
\hline
\end{tabular}

${ }^{a, b}$ farklı harfleri içeren ortalamalar arasında anlamlı bir farklılık vardır $(p<0,05)$.

\section{TARTIŞMA}

Öğrenci hemşirelerin bireysel ve örgütsel nedenlerle gelişen doyumsuzluklarının akademik başarılarına ve klinik uygulamalarına yansıması kaçınılmazdır. Bunun tersini de söylemek mümkündür. Klinik uygulamalarda öğrencilerin yaşadığı sıkıntılar akademik başarılarını etkileyecek ve doyumlarını azaltacaktır. Ayrıca öğrencilik döneminde yaşanan doyumsuzlukların, hemşirelik mesleğini olumsuz etkilemesi kaçınılmazdir.

Hemşirelik öğrencilerinin klinik uygulamalarının öğrencilerin doyumlarına etkisini değerlendirmek amacyyla yaptığımız bu çalışmada, öğrencilerinçoğununhemşireliğin çalışma şartlarının zorolması nedeniyle tedirgin olduğu tespit edilmiştir. Aşırı iş yükü hemşirelerde doyumu olumsuz etkileyen bir faktör olarak karşımıza çıkmaktadır. Kesgin ve Kublay (2011) çalışmalarında ağırçalışma koşullarının hemşirelerin sağlıklarını olumsuz etkilediği saptanmıştır. Uluslararası Hemşireler Birliği ve Pfizer'in ortaklaşa yaptığı 11 ülkeyi kapsayan bir araştırmada, hemşireliğin en olumsuz yanının (\%42) "iş yükü” olduğu tespit edilmiştir. Bu sonuçlar, hemşirelerin çalışma şartlarının zorluğununküresel bir sorun olarak devam ettiğini göstermektedir (ICN 2009).

Öğrenci memnuniyeti öğrencilerin akademik başarıs1n1 etkileyen önemli bir faktördür ve eğitiminin niteliğini göstermektedir (Ansari ve Stock 2010). Bununla birlikte hemşirelik öğrencileri ile yapılan çalışmalar, öğrencilerin klinik uygulamalarda yaşadıkları stresin, uygulamaların kısa süreli olmasının, klinik ortamın öğrenmeyi zorlaştırmasının ve uygulamaların iş merkezli olmasının öğrencilerin memnuniyetlerini azalttığını göstermektedir (Dutile, Wright ve Beauchesne 2011; Tosun ve ark. 2008). Çalışmamızda öğrencilerin çoğunun (\%63.6) kliniklerde keyifle ve huzurla çalışamadıklarıbelirlenmiştir. Karadağ, Kılıç, Ovayolu, Ovayolu ve Kayaaslan (2013)'nın çalışmalarına benzer şekilde, çalışmamızda öğrencilerin klinik uygulamalarda en fazla karşılaştıkları sıkıntılar; görevi dışında sorumluluk alma, teorik bilgilerin klinikte kullanılamaması ve alınan uygulamalı derslerle ilgili kliniklere 
çıkılmaması olarak belirlemiştir. Öğrenci sayılarının giderek artmasının, uygulama alanlarının kısıtlı olmasının veöğretim elemanlarının sayılarının yetersizliğinin bu sonuçlara neden olduğu düşünülmektedir.

Toplumla aynı hemşirelik algısınasahip hemşirelik öğrencilerinin bu algıları eğitimleri sırasında gerçek hemşirelik algısı ile yer değiştirir. Beklentileri ve alg1ları farklı olan öğrencilerin sınıflarına göre memnuniyet düzeyleri de değişmektedir. Literatürden farklı olarak (Baykal, Sökmen, Korkmaz ve Akgün 2005; Egelioğlu ve ark. 2011; Kaynar ve ark. 2006), bizim çalışmamızda hemşirelik 1. sınıf öğrencilerinin doyum puanlarının yüksek, 4. sınıf öğrencilerinin ise daha düşük olduğu belirlenmiştir.Son sınıftaki öğrencilerin mesleki beklentilerinin artmasının ve okul dışında da yoğun bir programa sahip olmalarının (memurluk, dil ve akademik sınavlara hazırlık, kısmi zamanlı / burslu öğrenci olarak çalışmak vb. gibi) öğrencilerin doyumlarını azalttığı düşünülmüştür.

Çalışmamızda klinik uygulamalarda keyifle ve huzurla çalışma imkânı bulduğunu, bir uygulamayı en iyi hemşirelerle birlikte yaptığını, klinik uygulamalarda en fazla hocalarından yardım aldığını ve klinik uygulama sırasında görevi dışında sorumluluk almadığını beyan eden öğrencilerin doyum puanları daha yüksek bulunmuştur ( $p<0,05)$. Karadağ ve ark. (2013)'nın çalışmalarında öğrencilerin üst sınıflara geçtikçe, klinik uygulamada hemşirelerden destek görme ve yardım alma oranının azaldığı, uygulamaları bağımsız yapma oranlarının anlamlı şekilde arttığı belirlenmiştir. Klinikte öğrenciler, özellikle kendi meslektaşlarından kabul ve destek gördüklerinde doyumları artmaktadır (Eskimez, Alparslan, Öztunç ve Torun 2005). Klinik uygulamanın başarısı, öğrencileri destekleyen servis hemşiresi ve sağlik ekibinin olduğu klinik ortamlarda artmaktadır (Konak, Dericioğulları ve Kılınç 2008). Çünkü klinik uygulamalar sırasında öğrencilerin yönlendirilmeye, desteklenmeye ihtiyacı vardır (Killam ve Carter 2010). Klinik ortamda hemşirelik öğrencilerinin ekip üyeleri ile birlikte çalışması, öğrenmelerini kolaylaştırmakta ve motivasyonlarını arttırmaktadır (Elçigil ve Sarı 2011). Böylece ekip içinde daha ak- tif olan öğrencinin doyumuartacak ve amaçlarını gerçekleştirmeye kendini daha çok adayacaktır (Elliot ve Shin 2002).

\section{SONUÇ VE ÖNERILER}

Araştırma sonuçlarına göre, öğrencilerin klinik uygulamalarda en fazla karşılaştıkları sıkıntılar klinik alanların yetersizliği ve sorumlulukları dışında görev almalarıdır. Çalışmamızda birinci sınıf öğrencilerinin doyum puanları daha yüksek bulunmuştur. Ayrıca kliniklerde hemşirelerle birlikte işbirliği yapan, hocalarından yardım alan ve klinik uygulama sırasında görevi dışında sorumluluk almayan öğrencilerin doyumları daha yüksektir.

Etkili klinik uygulama ortamlarının sağlanması için hastane-okul işbirliğginin arttırılmasının ve karş1lıklı beklentilerin paylaşılmasının yararlı olacağı düşünülmektedir. Öğrencilerin daha aktif görev almasının sağlanmasıyla öğrenci doyumunun artacağ1 ve klinik uygulamaların daha verimli hale geleceği düşünülmektedir. Bu hedeflere ulaşmak için öğrenci sayılarının azaltılması ve öğretim elemanı sayılarının arttırılmasının gerekliliği bir kez daha önem kazanmaktadır.

\section{KAYNAKLAR}

Ansari, W. E., Stock, C. (2010). Is the health and wellbeing of university students associated with their academic performance? Cross sectional findings from the United Kingdom. Int $J$ Environ Res Public Health, 7(2): 509-527.

Baykal, Ü., Sökmen, S., Korkmaz, Ş. (2002). Öğrenci Memnuniyeti Ölçeği geliştirme çalışması. Hemşirelik Dergisi, 12(49): 23-32.

Baykal, Ü., Harmancı, A. K., Eşkin, F., Altuntaş, S., Sökmen, S. (2011). Öğrenci Doyum Ölçeği - Kısa Form geçerlik güvenirlik çalışması. Anadolu Hemşirelik ve Sağllk Bilimleri Dergisi, 14(4): $60-68$.

Dutile, C., Wright, N., Beauchesne, M. (2011). Virtual clinical education: Going the full distance in nursing education. Newborn Infant Nurs Rev, 11(1): 43-48.

Egelioğlu, N., Arslan, S., Bakan, G. (2011). Hemşirelik öğrencilerinin memnuniyet durumlarının akademik başarıları üzerine etkisi. Hemşirelikte Araştırma Geliştirme Dergisi, 13(1): 14-24.

Elçigil, A., Sarı, H. Y. (2011). Hemşirelik öğrencilerinin klinik eğitiminde kolaylaştırıcı faktörler. DEUHYO ED, 4(2): 67-71. 


\section{Hemşirelik Öğrencilerinin Klinik Ortamdaki Doyum Düzeyleri ve Etkileyen Faktörler}

Elliot, K. M., Shin, D. (2002). Student satisfaction: An alternative approach to assessing this important concept. Journal of Higher Education Policy and Management, 24(2): 197-209.

Eskimez, Z., Alparslan, N., Öztunç, G., Torun, S. (2005). Hemşirelerin Adana Sağlık Yüksekokulu öğrencileri ve öğretim elemanlarının klinik uygulamalarına ilişkin görüşleri. Anadolu Hemşirelik ve Sağlık Bilimleri Dergisi, 8(3): 30-39.

International Council of Nurses (ICN) (2009). Nurses in the workplace: Expectations and needs. Nurses in the workplace: Expectations and needs, a global survey of nurses, http://www.icn.ch/images/stories/documents/news/advocacy/nursesintheworkplace/survey.swf (15.08.2015).

Kantek, F., Kazanc1, G. (2012). An analysis of the satisfaction levels of nursing and midwifery students in a health college in Turkey. Contemporary Nurse, 42(1): 36-44.

Karadağ, G., Kılıç, S. P., Ovayolu, N., Ovayolu, Ö., Kayaaslan H. (2013). Öğrenci hemşirelerin klinik uygulamada karşılaştıkları güçlükler ve klinik hemşireler hakkındaki görüşleri. TAF Preventive Medicine Bulletin, 12(6): 665-672.

Kaynar, A. ve ark. (2006). Karadeniz Teknik Üniversitesi Trabzon Sağlık Yüksekokulu Hemşirelik öğrencilerinin doyum düzeyleri. Cumhuriyet Üniversitesi Hemşirelik Yüksekokulu Dergisi, 10(3): 12-19.

Kesgin, M. T., Kublay, G. (2011). Özel bir hastanede çalışan hemşirelerin yaşam alışkanlıkları ve çalışma koşullarından kaynaklı sağlık sorunlarının değerlendirilmesi. Hacettepe Üniversitesi Sağlık Bilimleri Fakültesi Hemşirelik Dergisi, 18(1): 41-49.
Killam, L. A., Carter, L. M. (2010). Challenges to the student nurse on clinical placement in the rural setting: a review of the literature. Rural Remote Health, 10(3): 1523.

Konak, D. Ş., Dericioğulları, A., Kılınç, G. (2008). Burdur Devlet Hastanesi'nde çalışan hemşirelerinin klinik uygulamalarına ve öğretim elemanlarıyla işbirliği yapmaya ilişkin görüşleri. Süleyman Demirel Üniversitesi Tıp Fakültesi Dergisi, 15(1): 1-5.

Lee, C. Y., White, B., Hong, Y. B. (2009). Comparison of the clinical practice satisfaction of nursing students in Korea and the USA. Nursing and Health Sciences, 11(1): 10-16.

Özdelikara, A., Babur, S. (2016). Hemşirelik öğrencilerinin öğrenimlerine ilişkin doyum düzeyi ve etkileyen faktörler. DEUHFED, 9(1): 2-8.

Svetlana, A., Beltyukova, S. A., Fox, C. M. (2002). Student satisfaction as a measure of student development: towards a universal metric. Journal of College Student Development, 43(2): 161-169.

Tosun, N. ve ark. (2008). Hemşirelik yüksekokulu öğrencilerinin intörn eğitim programından beklentileri ile program sonunda kazanım ve önerilerinin değerlendirilmesi. Gülhane Tip Dergisi, 50(3): 164-171.

Türk Dil Kurumu (TDK) (2015). http//www.tdk.gov.tr/index.php? option=com_gts\&arama $=$ gts \&guid=TDK.GTS.55aff5c $1 \mathrm{df} 5 \mathrm{db} 9$. 82575310 (22.7.2015).

Yangın, H. B., Kırca, N. (2013). Antalya Sağlık Yüksekokulu hemşirelik öğrencilerinin memnuniyet düzeyleri ve etkileyen faktörler. Gümüşhane Üniversitesi Sağllk Bilimleri Dergisi, 2(1): 78-94. 